\title{
A Review on Service Broker Algorithm in Cloud Computing
}

\author{
Ruhani Jain \\ Amritsar college of \\ engineering and technology
}

Amritsar

\author{
Tejinder Sharma \\ Amritsar college of \\ engineering and technology \\ Amritsar
}

\author{
Narinder Sharma \\ Amritsar college of \\ engineering and technology
}

Amritsar

\begin{abstract}
This paper presents a cloud-based service broker which provides intermediation to seek appropriate service providers in terms of suitable trade-off between price and performance. It makes data centre selection and load balancing in cloud computing systems. The overall objective of this paper is to discuss the different available service broker algorithms and different cloud deployment models which confirm that it minimizes the cost performance and at the same time, witnessed gains in service performance.
\end{abstract}

\section{Keywords}

Cloud Computing, Cloud Deployment Model, Service Proximity algorithms.

\section{INTRODUCTION}

Cloud is getting important these days in IT industry. It provide services to customer on lease basis. Large organizations need not to own the resources they required .They can ask for resources from service provider. Service provider set some service level agreement to provide services. This help in low expenditure for the users because they have to only pay for what they are using. This is the most important feature of cloud computing. Cloud is a large pool of hardware and software resources which user can demand. This is a model which provide ease to user to select the services over the network. In this very low management effort is required. A cloud refers to a distinct IT environment that is designed for the purpose of remotely provisioning scalable and measured IT resources. The term 'Cloud' originated from Internet which is advancement of Internet in this we have access to decentralized IT resources over the network of networks. Cloud infrastructures area represented by services that are not only used, but also installed, deployed or replicated, with the help of virtualization. The services are applied in complex business processes that further complicate the fulfillment of Service Level Agreements (SLAs). For example, due to the changing components, workloads, external conditions, hardware, and software failures, established SLAs may be violated. Frequent user interaction with the system during SLA negotiations and service executions (which are usually necessary in the case of failures) may pose challenge to successful cloud Computing.

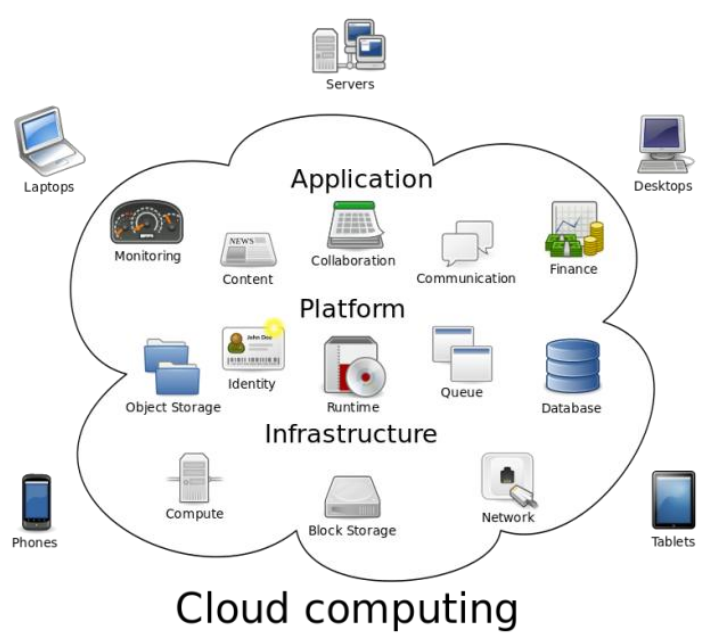

Fig 1: Cloud Computing

\subsection{Characteristics of Cloud Computing}

Cloud computing has five fundamental characteristics as follows:

1. On-demand self-service:

User can ask for resources required over the network for example it can ask for network space.

2. Broad network access:

Users can use cloud capabilities over different type of platforms for example PDA, laptop.

3. Resource pooling:

Cloud provider provide a large pool of resources to the user.. User can use the number of resources which he required from this pool.

\section{Rapid elasticity:}

The number of resources may increase or decrease as per the user demand. This capability is rapid in cloud.

5. Measured service:

Cloud system automatically controls and optimizes the resources usage by leveraging metering capability to the specific type of service. (E.g. Bandwidth, storage) .Resource usage is controlled, monitored and reported providing transparency for both cloud provider and customer.

\subsection{Cloud Deployment Models}

A cloud deployment model represents a specific type of cloud environment, primarily distinguished by ownership, size, and access. There are four common cloud deployment models:

1. Public Clouds - Public cloud is publicly available over the network. Any person on the network can avail the services 
available on this cloud with the agreement to the rules provided by the service provider. A third-party owns this cloud. Cloud is created with the above mentioned cloud delivery models. The services are offered to the consumer with the usage charges or some other service level agreements.

2. Community Clouds - The structure of community cloud is similar to public cloud with the restriction of it access. It can only be accessed between the community of consumers over the cloud not to every person available on the cloud. The owner of this community cloud can be community made by jointly group of persons or by a third-party cloud provider that restrict the access to cloud with limited users.

3. Private Clouds - A single organization own the private cloud. It purpose is to centralized the resources available so that different departments can use the services. A private cloud is owned by a single organization. Different part, departments and employees present can different locations can use the resources of the organization. This cloud computing technology plays a very important role in multination companies and can help in the reduction of cost.

4. Hybrid Clouds - With the combination of two or more different deployment models we can create hybrid cloud. For example, a cloud consumer may choose to deploy cloud services processing sensitive data to a private cloud and other, less sensitive cloud services to a public cloud.

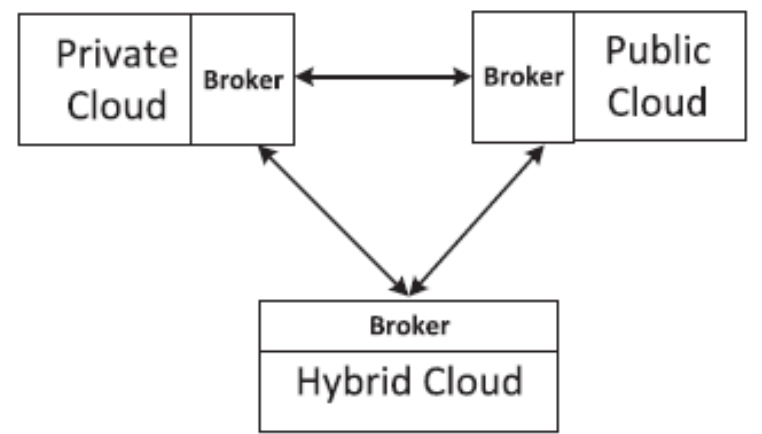

Fig 2: Cloud Service Model

\section{DIFFERENT TYPES OF SERVICE PROXIMITY ALGORITHMS}

\section{Hybrid Cost Performance service Broker Algorithm:}

This algorithm will consider two parameters (Cost \& Network /delay). Combining these two parameters is carried out in a way to give a lower cost with an acceptable response.

Two algorithms proposed;

I) one divides the load equally on the best performance data center and lowest cost one.

II) The second considers both cost and performance parameters when choosing the datacenter (DC).

Working: The Hybrid Cost - Performance Service Broker proposed algorithms are proposed to select the destination datacenter by considering two important parameters, the response time and total Cost. Examining the proposed algorithms versus the existed algorithms with two different scenarios proved the best response possible with the lowest cost of the proposed ones. Results show enhancements with a percentage up to $30 \%$ in total cost, $8 \%$ in response time, and $10 \%$ in processing time comparing to other already developed algorithms.
Problem: It needs a new optimized load balancer to lower the response time for any datacenters.

\section{Static Service Broker Algorithm:}

This algorithm enhance results in reduction of data center loading, request timing, costing of $\mathrm{VM}$ and cost of data transfer. This service broker algorithm is combination of advantages of Service Proximity Service Broker and Weighted Round Robin Service Broker Algorithm. . In Service Proximity Service Broker the earliest region is selected based on the minimum communication delay and maximum available bandwidth from user base (client) to data center residing region. In Weighted Round Robin Service Broker algorithm the data centre selection is done based on the processing capacity of respective data center.

Working: This algorithm optimizes the number of connections and reduces average DC request service timing. Finally, experiments show that proposed algorithm improves the performance of existing SPSB algorithm.

Problem: Average DC costing timing need to improve more.

\section{Enhanced Proximity-Based Routing Policy:}

This algorithm is based on the enhancement of proximitybased routing policy which avoids the overloading of the nearest data center by routing the traffic to the neighboring data center in the same region which improve response time by reducing the chances of SLA violation and enhancing the response time of the data center.

Working: By the experimentation result is improved by $17 \%$ for response time.

\section{Extended Priority based Round-Robin Selection:}

In order to overcome the problem of service proximity service broker algorithm instead of selecting data center randomly, proposed service broker use Round Robin fashion to select the datacenter in which it can select datacenter with fast speed or datacenter with slow speed. It lead to more resource utilization

But for more performance we need to select data centre with fast speed, they should be selected more number of times. But to reduce the cost factor we need to select less costly datacenter more number of times. So we have to select the data center in proportion of their Rating. He has used Preprocessing algorithm in the beginning of the simulation to create priority list. This list contains sequence of index of data center indexed by their region. Preprocessing step will be executed only once. After Preprocessing, Data Center Selection algorithm uses the priority list to select the data center for each region.

Problem: The results of simulation can be concluded that proposed algorithm works efficiently when it comes to resource utilization, processing time of the data center and response time of user base. In proposed extended priority based Round-Robin selection algorithm author find the optimal value of $\mathrm{R}$ (rating factor), which enables to get desired performance and cost. These algorithms can be improved in future by introducing new equation for the rating calculation.

\section{Load aware brokering algorithm:}

Load balancing are of two types static and dynamic.Variation of load is high in cloud computing . Static algorithms are not suitable for a cloud computing environment. This dynamic load balancing is successfully used in cloud and dynamic algorithms handle changing workloads over time. The loadaware algorithm distributes all requests among all available 
data centers. The resource selection uses a load balancing technique; the processing time is reduced if the jobs are distributed among various data centers. But this could lead to increase in operational costs.

\section{Cost Aware Brokering Algorithm:}

We use two different policies to discover the available resources for users, along with a unique algorithm for each. The algorithm for resource selection over cost and load, regional list is a list of regions in which data centers are located. The dc cost load list holds cost and load wise list for future allocation. The sm holds the dc Name of the lowest cost. Cost-aware brokering algorithms always select the VM with the lowest cost. They also always update the list if an available lowest cost VM is found.

\section{RELATED WORK}

R. Thomas et al. [1] propose the improvement in the quality of standards and implementation by using the developed testing method at European Telecommunications Standards Institute (ETSI). N. R. Ranjan et al. [3] proposed cloud sim toolkit. Using this toolkit modeling and simulation of cloud computing system and applications providing enviorment is created and its results can be verified.With the help of this toolkit datacenter usage and virtual machine availability van be controlled. It support both system and modeling behavior of cloud components. Rochwerger, Benny, et al. [4] introduce the federation of cloud which is formed by the mutual agreement on certain set of rules so the load balancing and the scalability of resources can be managed to control the costing issue. A. Sarfaraz Ahmed et al. [5] propose an algorithm which help to control the traffic to data center. This algorithm help to choose the nearest available data centre with in the same region to reduce overloading problem. It enhance the proximity-based routing policy. Ali Naser et al. [6] studied different existing load balancing algorithm and proposed and algorithm which will help in improvement in response time and help to reduce data processing time and cost. Tushar Desai et al. [8] discussed existing load balancing techniques and diffenertiate them on the basis of their performance. Tejinder Sharma, et al. [11] analyzed the performance of existing load balancing algorithms with different service broker policies. Rakesh Kumar et al. [12] propose priority and extended priority based Round- Robin service broker algorithms which distribute the requests based on the Rating of data centers and gives better performance than the conventional Random selection algorithm. Gamal I. Selim et al. [13] propose two algorithms to choose appropriate data centre which help in the reduction of cost and improvement in performance. In this region, datacenter and cost is considered in the selection of data centre. Two testing scenarios are considered to compare the proposed algorithms with three existing algorithms. Mayanka Katyal et al. [14] calculate the performance of existing algorithm using cloud simulator and purpose new algorithm bases on min min and max min technique to improve the performance of cloud environment. Deepak Kapgate, et al. [16] proposed an algorithm for the selection of data centre. The focus of this algorithm is to reduce the response time and improve the cost of processing. He prove his result with the comparison among proposed and existing algorithms. Naha et al. [17] suggest a new algorithm to reduce the cost and improve the performance. It assist the user to find appropriate service broker according to their requirements. Ranesh Kumar et al. [18] proposed three different cloud brokering algorithms, and a load balancing algorithm. A simulation based deployment confirms that our proposed algorithms minimized the cost, and at the same time, witnessed gains in service performance.

\section{GAPS IN LITERATURE}

There are various gaps in literature survey on cloud computing algorithms:

1. The majority of the existing service broker algorithm are based upon bivalent logic which limit its performance.

2. The use of Fuzzy aware service broker algorithm is also ignored in existing literature.

3. Also the effect of communication overhead is ignored in most of the existing service broker techniques.

\section{COMPARISON TABLE}

\begin{tabular}{|l|l|l|l|l|l|l|}
\hline \multicolumn{1}{|c|}{ Name of author } & \multicolumn{1}{|c|}{$\begin{array}{c}\text { Title of the } \\
\text { paper }\end{array}$} & Year & Techniques & $\begin{array}{c}\text { Cost } \\
\text { Performance }\end{array}$ & $\begin{array}{l}\text { Response } \\
\text { Time }\end{array}$ & $\begin{array}{c}\text { Processing } \\
\text { Time }\end{array}$ \\
\hline Thomas Rings & $\begin{array}{l}\text { Grid and Cloud } \\
\text { Computing } \\
\text { Opportunities } \\
\text { for Integration }\end{array}$ & 2009 & $\begin{array}{l}\text { grid and cloud } \\
\text { computing } \\
\text { strategies }\end{array}$ & Decreases & Decreases \\
\hline
\end{tabular}




\begin{tabular}{|c|c|c|c|c|c|c|}
\hline Bernstein, David & $\begin{array}{l}\text { An inter cloud } \\
\text { cloud } \\
\text { computing } \\
\text { economy- } \\
\text { technology }\end{array}$ & 2011 & $\begin{array}{l}\quad \text { create } \\
\text { blueprints for } \\
\text { comprehensive } \\
\text { governance }\end{array}$ & Increases & Decreases & Increases \\
\hline Rochwerger & $\begin{array}{l}\text { Reservoir- } \\
\text { when one cloud } \\
\text { is not enough }\end{array}$ & 2011 & federated cloud & Increases & Decreases & Increases \\
\hline A. Sarfaraz Ahmed, & $\begin{array}{l}\text { Enhanced } \\
\text { Proximity- } \\
\text { Based Routing } \\
\text { Policy for } \\
\text { Service } \\
\text { Brokering in } \\
\text { Cloud } \\
\text { Computing }\end{array}$ & 2012 & $\begin{array}{l}\text { proximity-based } \\
\text { routing policy }\end{array}$ & Average & Average & Increases \\
\hline Ali Naser & $\begin{array}{l}\text { An Efficient } \\
\text { Load Balancing } \\
\text { Algorithm for } \\
\text { virtualized } \\
\text { Cloud Data } \\
\text { Centers }\end{array}$ & 2012 & $\begin{array}{l}\text { Load Balancing } \\
\text { algorithms }\end{array}$ & Increases & Decreases & Decreases \\
\hline Dhaval Limbani & $\begin{array}{l}\text { A Proposed } \\
\text { Service Broker } \\
\text { Strategy in } \\
\text { Cloud Analyst } \\
\text { for Cost- } \\
\text { Effective Data } \\
\text { Center } \\
\text { Selection }\end{array}$ & 2012 & $\begin{array}{l}\text { Service Broker } \\
\text { Algorithms, Load } \\
\text { balancing } \\
\text { algorithms }\end{array}$ & Increases & Increases & Increases \\
\hline Tushar Desai & $\begin{array}{l}\text { Survey Of } \\
\text { Various Load } \\
\text { Balancing } \\
\text { Techniques } \\
\text { And Challenges } \\
\text { In Cloud } \\
\text { Computing }\end{array}$ & 2013 & $\begin{array}{l}\text { Load Balancing } \\
\text { Techniques }\end{array}$ & Increases & Decreases & Increases \\
\hline Gamal I. Selim, & $\begin{array}{l}\text { An Efficient } \\
\text { Cloud Service } \\
\text { Broker } \\
\text { Algorithm }\end{array}$ & 2014 & $\begin{array}{l}\text { Service Broker } \\
\text { Algorithm }\end{array}$ & Decreases & Decreases & Increases \\
\hline Naha, R.K., & $\begin{array}{l}\text { Evaluation of } \\
\text { cloud brokering } \\
\text { algorithms in } \\
\text { cloud based } \\
\text { data center }\end{array}$ & 2015 & $\begin{array}{l}\text { Cloud Brokering } \\
\text { algorithms }\end{array}$ & Decreases & Increases & Increases \\
\hline
\end{tabular}

\section{CONCLUSION}

On-demand resource provisioning makes cloud computing a cutting edge technology. All cloud service providers offer computing resources with their own interface type, instance type, and pricing policy, among other service features. In this paper we have discuss the cloud deployment models and various algorithms based on cloud computing which confirms and minimizes the cost performance and at the same time, witnessed gains in service performance. But there are still some issues regarding the cost performance and response time. In near future we will evaluate the performance 
substantially by improving response time using new algorithm.

\section{REFERENCES}

[1] Thomas Rings-Geoff Caryer-Julian Gallop, Grid and Cloud Computing Opportunities for Integration with the Next Generation Network, Received: 7 November 2008 / Accepted: 13 August 2009 (C) Springer Science + Business Media B.V. 2009

[2] Bernstein, David, Deepak Vij, and Stephen Diamond. "An intercloud cloud computing economy-technology, governance, and market blueprints." 2011 Annual SRII Global Conference. IEEE, 2011.

[3] Calheiros, N. R. "Ranjan. R, Beloglazov. A, De Rose. ACF, and Buyya. R, "CloudSim: A Toolkit for Modeling and Simulation of Cloud Computing Environments and Evaluation of Resource Provisioning Algorithms"." Software: Practice and Experience (SPE) 2011

[4] Rochwerger, Benny, et al. "Reservoir - when one cloud is not enough." IEEE computer 44.3 (2011): 44-51.

[5] A. Sarfaraz Ahmed, Enhanced Proximity-Based Routing Policy for Service Brokering in Cloud Computing, International Journal of Engineering Research and Applications (IJERA) ISSN: 2248-9622 Vol. 2, Issue 2,Mar-Apr 2012, pp.1453-1455

[6] Ali Naser Abdulhussein Abdulhussein, Jugal Harshvadan Joshi, Atwine Mugume Twinamatsiko, Arash Habibi Lashkari, Mohammad Sadeghi, An Efficient Load Balancing Algorithm for virtualized Cloud Data Centers, Recent Advances in Electrical and Computer Engineering ISBN: 978-1-61804-228-6

[7] Dhaval Limbani, Bhavesh Oza, A Proposed Service Broker Strategy in CloudAnalyst for Cost-Effective Data Center Selection, International Journal of Engineering Research and Applications (IJERA) ISSN: 2248-9622 Vol. 2, Issue 1, Jan-Feb 2012, pp.793-797

[8] Tushar Desai, Jignesh Prajapati, A Survey Of Various Load Balancing Techniques And Challenges In Cloud Computing, international journal of scientific \& technology research volume 2 , issue 11 , november 2013 issn $2277-8616$
[9] Upendra Bhoi and Purvi N. Ramanuj, Enhanced Maxmin Task Scheduling Algorithm in Cloud Computing, International journal of application or Innovation in engineering and managment(IJAIEM) Volume 2, Issue 4, April 2013 ISSN 2319 - 4847

[10] MR.Manan D. Shah,MR.Amit A. Kariyani and MR.Dipak L. Agrawal, Allocation Of Virtual Machines In Cloud Computing Using Load Balancing Algorithm, IRACST - International Journal of Computer Science and Information Technology \& Security (IJCSITS), ISSN: 2249-9555 Vol. 3, No.1, February 2013

[11] Tejinder Sharma, Vijay Kumar Banga, Efficient and Enhanced Algorithm in Cloud Computing, International Journal of Soft Computing and Engineering (IJSCE) ISSN: 2231-2307, Volume-3, Issue-1, March 2013

[12] Rakesh Kumar Mishra, Sreenu Naik Bhukya, Service Broker Algorithm for Cloud-Analyst, International Journal of Computer Science and Information Technologies, Vol. 5 (3) , 2014, 3957-3962

[13] Gamal I. Selim, Rowayda A. Sadek and Hend Taha, an Efficient Cloud Service Broker Algorithm, International Journal of Advancements in Computing Technology (IJACT) Volume 6, Number 1, January 2014

[14] Mayanka Katyal and Atul Mishra, Application of Selective Algorithm for Effective Resource Provisioning In Cloud Computing Environment, International Journal on Cloud Computing: Services and Architecture (IJCCSA), Vol. 4, No. 1, February 2014

[15] Ms.NITIKA, Comparative Analysis of Load Balancing Algorithms in Cloud Computing, Research Invent : International Journal of Engineering and Science Vol 1Issue 1 January 2014

[16] Prof. Deepak Kapgate, Efficient Service Broker Algorithm for Data Center Selection in Cloud Computing, International Journal of Computer Science and Mobile Computing, Vol.3 Issue.1, January- 2014, pg. 355-365

[17] Naha, R.K., Othman, M., Akhter,N.,2015.Evaluation of cloud brokering algorithms in cloud based data center. Far EastJn.Commun.15, 85-98.

[18] Naha, Ranesh Kumar, and Mohamed Othman. "Costaware service brokering and performance sentient load balancing algorithms in the cloud." Journal of Network and Computer Applications 75 (2016): 47-57. 